\title{
Do socio-demographic groups report different attitudes towards water resource management? Evidence from a Ghanaian case study
}

\author{
Murat Okumah · Priscilla Ankomah-Hackman - Ata Senior Yeboah
}

Published online: 12 March 2020

(C) The Author(s) 2020

\begin{abstract}
Understanding the influence of socio-demographic factors on attitudes towards water pollution mitigation measures could help provide good pointers in the design of effective water resources management policies. Yet, very few studies have examined this in the developing country context. Using quantitative methods to analyse survey data from Ghana, the main goal of the current study was to determine whether socio-demographic groups report different attitudes towards water resource management. Results show that females reported higher pro-environmental attitudes than men (and these differences were statistically significant). Additionally, the employed were found to have reported higher pro-environmental attitudes than students and the unemployed, however,
\end{abstract}

M. Okumah $(\square)$

Sustainability Research Institute, University of Leeds, Leeds LS2 9JT, England, UK

e-mail: ee15sa@leeds.ac.uk

P. Ankomah-Hackman

Jesus College, University of Cambridge,

Cambridge CB1 8BL, England, UK

P. Ankomah-Hackman

Habitat for Humanity, Greater Toronto Area, 155

Bermondsey Road Toronto, Toronto ON M4A 1X9,

Canada

\section{A. S. Yeboah}

Department of Planning, Faculty of Built Environment, Kwame Nkrumah University of Science and Technology,

Kumasi, Ghana we do not find evidence to support the influence of age and educational attainment. Notwithstanding the relatively limited sample, this work offers valuable insights into the different factors that could influence environmental attitudes. Further research is needed on how sociodemographic variables interact with other psychosocial factors to determine environmental attitudes. This could advance our understanding on how different social groups may respond to policies designed to promote pro-environmental behaviour and reduce water pollution.

Keywords Environmental attitudes · Proenvironmental behaviour - Water pollution - Gender . Employment status · Ghana

\section{Introduction}

Water pollution remains a major global problem, with impacts on human health, ecosystems and costs of water treatment (United Nations Environment Programme 2017; OECD 2012; United Nations World Water Assessment Programme 2015). This poses a major challenge to all stakeholders interested in water quality, such as governments, intergovernmental organisations, and communities (OECD 2012). The Sustainable Development Goals (SDGs) provide, at the international level, the policy framework for responding to the problem. Indeed, SDG 6 specifically 
aims at ensuring the availability and sustainable management of water and sanitation for all (United Nations 2016a, b). The realisation of this goal requires far-reaching policy actions from national governments. Importantly, the success of national water policies depends on public awareness and environmental attitudes.

Understanding people's attitudes is therefore crucial to promoting behaviours that reduce water pollution. There is a considerable volume of research that explores environmental attitudes (e.g., Okumah et al. 2018, 2020; Okumah et al. 2019a, b), but fewer studies have investigated the underlying factors of such attitudes (Beiser-Mcgrath and Huber 2018). Furthermore, only a limited volume of research explore the role of socio-demographic factors in attitude formation and prediction. The limited research on sociodemographic factors have shown that relatively younger persons, females, well-educated, and people who are economically well positioned are more proenvironmentally inclined (Blocker and Eckberg 1989, 1997; Mensah 2012; Franzen and Vogl 2013).

While these findings offer useful insights into the drivers of environmental attitudes, their applicability may be affected to a large extent, by the political, cultural and socio-economic circumstances of different places-raising questions about transferability (Bryman 2008). Phenomena, attitudes and behaviours are not easily understood on their own; they need to be examined and explained in context, to help us arrive at valid interpretations. This, in turn, provides a good foundation for sound comparisons across different levels of environmental governance. Therefore, the potential influence of socio-demographic factors need to be examined within the developing country context. Understanding the influence of these variables may provide good pointers in the design of context-specific policies needed to promote sustainable water resources management (Okumah and Yeboah 2019; Okumah et al. 2019a, b).

Following this, the present study seeks to address the question; do socio-demographic groups report different attitudes towards water resource management? In answering this question, we apply quantitative methods to analyse survey data from Ghana. Specifically, we rely on survey data from coastal communities in the Greater Accra Region, Ghana to explore whether there are statistically significant differences between environmental attitudes reported by different groups (based on age, gender, employment status and educational attainment).

The remainder of the paper is structured as follows: In the next section, we provide an overview of the literature on environmental attitudes and factors driving attitudes. Next, we discuss the materials and methods applied in the study. This is followed by a presentation of results and discussion of key findings. Section "Limitations and future research" covers limitations of the paper, followed by concluding remarks.

\section{Overview of the literature}

Understanding environmental attitudes and the need to study attitudes

Environmental attitudes are relatively permanent positive or negative feelings an individual hold about an environmental issue (Schultz et al. 2004). It is argued that environmental attitudes are key drivers of behavioural intentions and pro-environmental behaviour. That is, people with positive environmental attitudes are more likely to have intentions to act proenvironmentally, and these intentions could translate into adoption of environmentally responsible practices (e.g., Ajzen and Fishbein 1980). This hypothesis has been confirmed in many empirical studies (e.g., Okumah et al. 2019a, b; Erdogan et al. 2013; Bogner 2000).

Because attitudes appear to be good predictors of many environmental behaviours, a considerable volume of studies have focussed on understanding environmental attitudes. Thompson and Barton (1994) argue that environmental attitudes may be embedded in people's concern for humans or living things (i.e., environmental consciousness), which may be related to their knowledge of environmental issues. For instance, some people could develop negative environmental attitudes due to poor environmental knowledge. Therefore, understanding attitudes and the drivers of such attitudes could deepen policymakers' knowledge on how to influence various attitudes in relation to environmental issues (Morris and Potter 1995, Young et al. 1995). 
Factors influencing environmental attitudes

There is controversy regarding the drivers of many environmental attitudes. Previous research has established that economic factors could be potential predictors of environmental attitudes (e.g., Zelezny et al. 2000). For example, some studies have established that rich nations are more likely to show greater concerns for the environment. A possible reason for this is that, relatively wealthy countries have moved beyond fundamental economic needs and are therefore more likely to consider the impact of their activities on the environment. This suggests that income might influence people's attitudes towards the environment. This conclusion suggests a deterministic view that if one is poor, one is likely to have negative environmental attitude. However, this might not be the case in some circumstances because some poor people may be environmentally concerned because they need to protect environmental resources upon which they depend for livelihoods (Chambers 1987). Second, limiting wealth to income may not be applicable to some rural areas in developing countries where people often value wealth (and worth) by how much cattle holdings and land a person holds (Gray and Moseley 2005). Therefore, while environmental attitudes may be driven by income, this may differ in different context, and needs to be investigated.

Zelezny et al. (2000) established a potential gender dimension in their study as women reported stronger positive environmental attitudes than their male counterparts. This finding has been attributed to the fact that most household and domestic roles are undertaken by women, who in turn rely greatly on environmental resources (e.g., water). This is because while men and women depend on forest and water resources as important livelihood sources, evidence suggests that women exhibit positive environmental attitudes than males essentially because women depend greatly on the services provided by the environment to undertake their household and domestic activities, such as using forest products and water resources for cooking. Moreover, in most rural areas in developing countries, women are directly engaged in fetching water from many surface waters (e.g., streams) and could observe the state of water resources.

Similarly, some scholarly works have underscored the influence of age in determining environmental attitudes (e.g., Zeus and Reif 1990). Zeus and Reif (1990) evidence suggests that environmental attitudes appear to be positive among younger age cohorts. A possible explanation for this is that young people are more likely to have been exposed to environmental education and are therefore more likely to be environmentally conscious. Moreover, a study conducted by Eagles and Demare (1999) found a strong positive correlation between environment attitudes with discussing environmental issues at home, watching films regarding nature and reading documents that are of environmental concern. The authors argue that the extent to which an individual would demonstrate sound environmental attitude is contingent on his long-term exposure to issues of environment, thus, serving as a critical driver of environmental attitudes.

While some studies demonstrate the potential role of education on attitude formation, further evidence suggests that the influence of education might be affected by other factors due to a potential interaction between education and for example, income. These studies (e.g., Zelezny et al. 2000; Karpiak and Baril 2008; Erdogan et al. 2013) provide evidence that highly educated persons with substantial income earnings appear to be more environmentally conscious. Further efforts are therefore required to disentangle the true effect of education and income and how the two interact (with other variables) to drive environmental attitudes.

Yet, other studies show that values, norms and beliefs system are important drivers of environmental attitudes (e.g., Kasser 2011; Stern and Dietz 1994; Schultz and Zelezny 1999) as well as world views (Martin-Ortega et al. 2017). These authors make a strong case for values and belief systems as instrumental drivers of environmental attitude, given that the values, norms and beliefs of a given society determines what is proper or improper in that society and serves as principles that govern behaviours. Therefore, whether people would have pro-environmental attitudes or not depends largely on the prevailing value systems and norms. For example, in cultures where issues of environmental concern are prominent and punitive sanctions are meted out where appropriate, it is likely that people will develop a strong concern for the environment.

The evidence reviewed here seems to suggest the potential role of socio-demographic variables as drivers of environmental attitudes. However, some 
controversies exist regarding for example, the role of income. Moreover, there are questions regarding the role of education given that education interacts with other variables (e.g., income). It is also important to note that studies exploring drivers of environmental attitudes tend to focus considerable attention on developed nations and this may have limited contextual relevance for developing countries. As discussed earlier, the socio-cultural and economic differences across regions implies that the explanatory power of various variables may vary significantly across regions, thus the need to investigate the role of these variables in the developing country context.

\section{Materials and methods}

\section{Materials}

The data used in this paper were gathered through an online survey conducted in Ghana in October 2018. The participants were drawn from members of the Ghanaian public located in coastal communities in Accra, the country's capital. A questionnaire was used to operationalize the variables of interest: attitude and socio-demographic characteristics-age, gender, educational level, and employment status of respondents. Three statements were used to elicit attitudes of survey participants towards water resources pollution, with a focus on the intrinsic motivations for reducing water pollution. These statements include: "I welcome the idea of stopping illegal mining in order to reduce water pollution", "I support the cause to reduce the problem of water pollution because it has an effect on our health and other living organisms" and "I support the cause to reduce the problem of water pollution because it is bad for the environment and future generations." A five-point Likert scale was used to evaluate attitudes: 1 (strongly disagree) to 5 (strongly agree). Higher scores indicate strong pro-environmental attitudes while lower scores point to weak pro- environmental attitudes towards water resources management.

Overall, 281 survey responses were obtained. We applied the standard deviation technique of detecting unengaged responses. From the standard deviations of responses, we observed that three cases showed a standard deviation of zero, indicative of non-engagement and were deleted after close examination. Thus, two hundred and seventy-eight (278) responses formed the basis of our analysis (additional information on the data used in this study has been reported in Okumah and Ankomah-Hackman 2020).

Analytical methods

The construct "attitude" was derived from a combination of three items, which are assumed to be unidimensional (Babbie 1999). The assumption of unidimensionality was tested using Cronbach's Alpha. An alpha of 0.70 or higher is strongly recommended, suggesting that the items are internally consistent (Cronbach 1951).

Next, we examined the data to check normality and other conditions for performing one-way Analysis of Variance (ANOVA) or the Welch test. We discovered that the data showed a non-normal distribution. The data was then transformed using the base 10 logarithm function (LOG10) to improve distribution. Following this, we performed the ANOVA test and the Welch test. The Welsh test does not assume equality of variances in the data, thus, making it robust and statistically powerful where the assumption of equality of variances is violated. Attitude was classified as the dependent variable while socio-demographic variables were included as independent factors. Socio-demographic variables were coded as: Male = 1 , Female $=2$; No university degree $=1$, university degree $=2$, further degrees $=3$; unemployed $=1$, student $=2$, and employed $=3$, for gender, education and employment status respectively. The ANOVA test and the Welch test were performed using SPSS IBM version 23 .

\section{Results and discussion}

Distribution of survey participants across sociodemographic characteristics

The results in Table 1 show that the survey was dominated by males. Survey participants were somewhat young, with a median age of $26 .{ }^{1}$ Approximately

\footnotetext{
${ }^{1}$ We report the median because the data was not normally distributed: (Kolmogorov-Smirnov statistic $=0.328 ; d f=278$; $p$ value $<0.001)$, thus making the median reliable than the mean (26.5; SD 4.6).
} 
Table 1 Sociodemographic characteristic of respondents
Median $=26 ; \mathrm{N}=277$

$\mathrm{N}=278$ for all variables;

$\mathrm{N}=277$ for age variables

\begin{tabular}{lll}
\hline Variable & Groups & Percentage \\
\hline Gender & Male & 67.8 \\
& Female & 32.2 \\
Educational attainment & Without university degree & 14.3 \\
& With university (first) degree & 61.9 \\
& With a minimum of a second university degree & 23.8 \\
Employment status & Unemployed & 20.0 \\
& Student & 38.8 \\
& Employed & 41.7 \\
Age classification & Group 1: Young (below median age) & 45.1 \\
& Group 2: Median age and above & 54.9 \\
\hline
\end{tabular}

Table 2 Descriptive results of respondents' evaluation of survey item $(n=278)$

\begin{tabular}{|c|c|c|}
\hline Items & Mean & SD \\
\hline I welcome the idea of stopping illegal mining in order to reduce water pollution & 4.80 & 0.62 \\
\hline $\begin{array}{l}\text { I support the cause to reduce the problem of water pollution because it has an effect on our health and other living } \\
\text { organisms }\end{array}$ & 4.90 & 0.49 \\
\hline $\begin{array}{l}\text { I support the cause to reduce the problem of water pollution because it is bad for the environment and future } \\
\text { generations }\end{array}$ & 4.91 & 0.47 \\
\hline
\end{tabular}

Overall mean $=4.87 ;$ overall standard deviation $=0.47$ Cronbach's Alpha $=0.87$

I support the cause to reduce the problem of water pollution because it is bad for the environment and future generations $(\mathrm{N}=278)$

I support the cause to reduce the problem of water pollution because it has an effect on our health and other living organisms $(\mathrm{N}=278)$

I welcome the idea of stopping illegal mining in order to reduce water pollution $(\mathrm{N}=278)$

$$
\begin{aligned}
& \text { Completely disagree } \quad \text { Somewhat disagree } \\
& \text { Fig. } 1 \text { Respondent's views regarding water pollution } \\
& 85 \% \text { had a university degree or higher qualifications, } \\
& \text { with about } 40 \% \text { of total participants being employed. }
\end{aligned}
$$
with about $40 \%$ of total participants being employed.
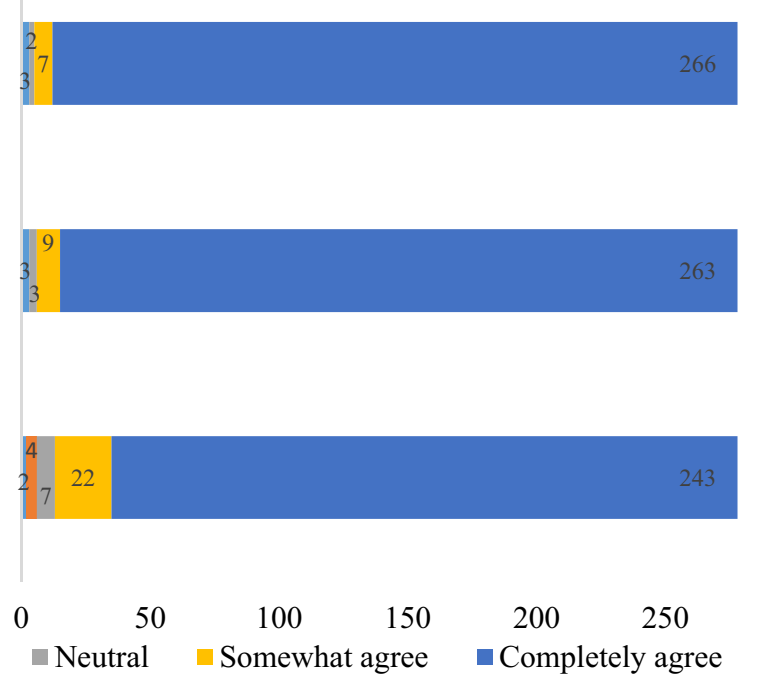

300

\section{Overview of survey responses}

The results in Table 2 show that generally, respondents reported high pro-environmental attitudes, 
suggesting that survey participants have a positive attitude towards water resources management (see also Fig. 1). The lowest mean score (4.80) was recorded for the attitudinal statement on stopping illegal mining. This may suggest that while people feel positive about protecting water resources, economic motivations may reduce their desire to protect water resources. Cronbach's Alpha (0.87) is well above the recommended threshold of 0.7 ., indicating a high internal consistency among scale items.

Do socio-demographic groups report different attitudes towards water resource management?

The first variable explored was gender. Levene's test of equality of variances showed that the variances in reported attitudes within groups were not equal: $\mathrm{F}_{(1,274)}=4.907, p=0.028$. The results of Welch test showed that there was a statistically significant difference between group means: $\mathrm{F}_{(1,260.952)}=3.197, p<0.1$, with females reporting higher pro-environmental attitudes (Fig. 2).

Our results are consistent with those of Mostafa (2007) and Mensah (2012) who found that women reported stronger concern for the environment. The higher emotional attachment and environmental concern has been linked to their gender socialization (Mostafa 2007) and value systems (Hunter et al. 2004). If cultural systems are such that females engage more in household activities that are directly linked to water management, they are more likely to be conscious of the links between human activities, water wastage and pollution (Okumah et al. 2019a, b).

The link between gender and environmental attitudes is complex. People's motivations and other factors (e.g., moral norms) influence the complex interactions between gender and environmental attitudes (e.g., Okumah et al. 2019a, b). The extent of the influence of motivations on the gender-attitude link could determine the influence of gender on environmental attitudes: where these elements have a high influence, the gender-attitude link may be non-existent or weak at best. This could explain why some studies (e.g., Tindall et al. 2003) found results that are contradictory to our findings.

For employment status, Levene's test showed that the variances for environmental attitudes were not equal, $F_{(2,261)}=6.507, p=0.002$. The results of Welch test show that there were statistically significant differences between group means,

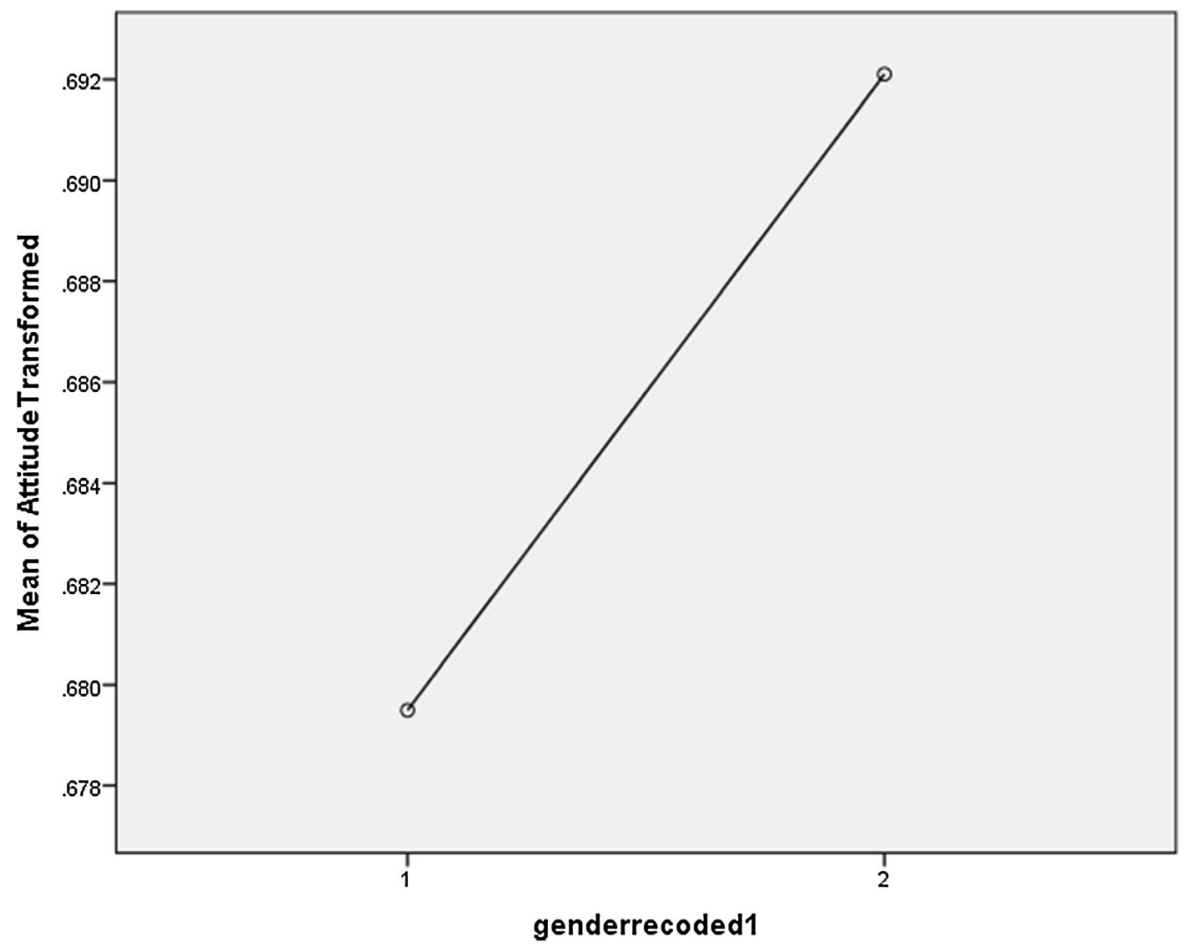

Fig. 2 Group means for gender categories. Note: Male $=1 ;$ Female $=2$ 


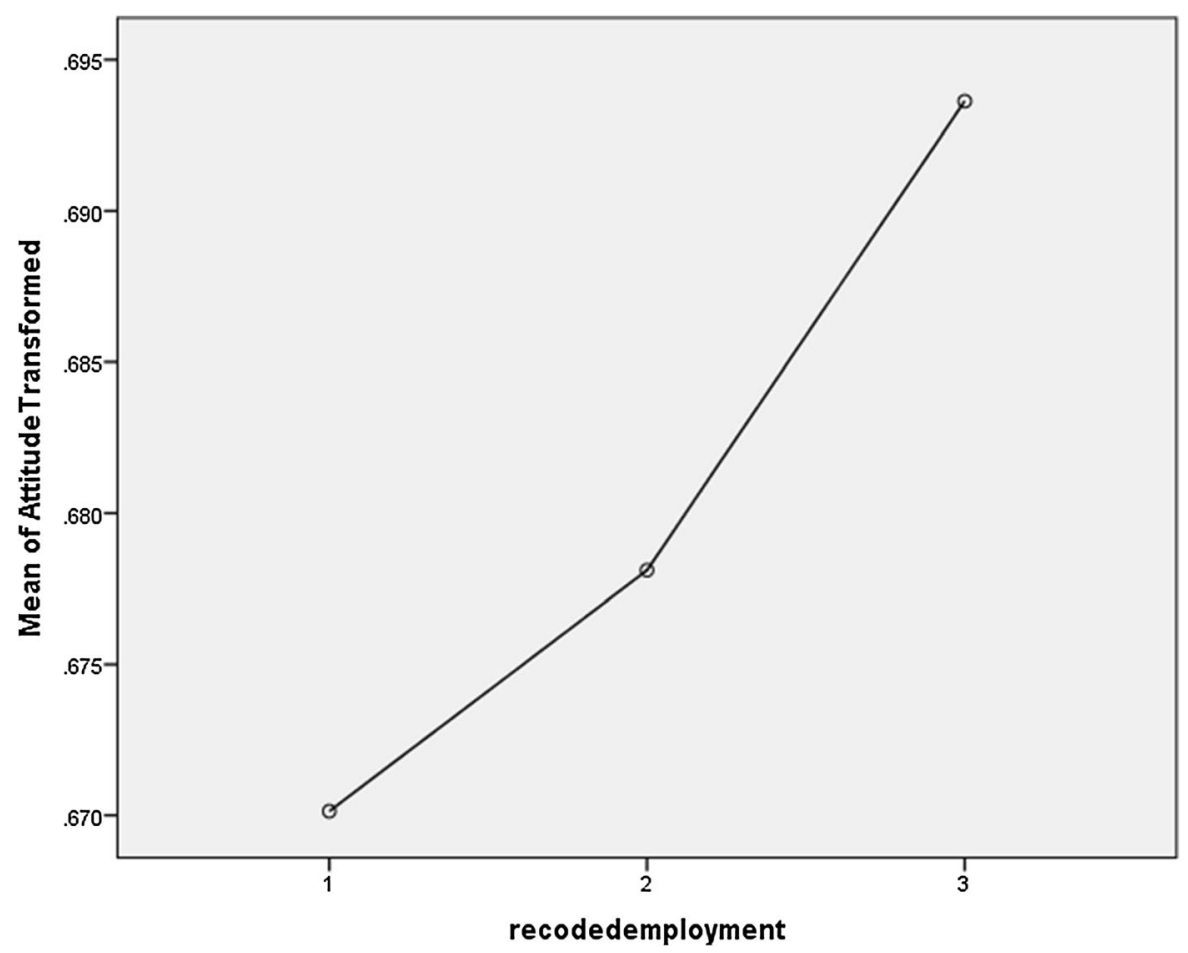

Fig. 3 Group means for employment categories. Note: Unemployed $=1$; Student $=2$; Employed $=3$

$F_{(2,}$ 94.639) $=2.683, \quad p<0.1$. People who were employed reported the highest environmental attitudes, followed by students, with the unemployed reporting the lowest (Fig. 3). As other studies have shown, people who are economically well positioned are more likely to be more environmentally concerned and willing to support environmental management efforts because such individuals have less economic challenges to worry about (e.g., Franzen and Vogl 2013). Indeed unemployed people are likely to be less concerned about the environment even when they know the consequences of environmental degradation. Such relatively weak pro-environmental attitudes may be due to the need for a source of livelihood, which could 'push' the unemployed into economic activities that have potential environmental impacts. This may explain why among the three attitudinal statements, 'stopping illegal mining for water protection' scored the least.

While unemployment may affect people's environmental attitudes, we acknowledge the complexity of factors that account for environmental attitudes and therefore reject the deterministic view that 'if you're poor, you degrade'. This is because some poor people may be environmentally conscious due to the need to protect environmental resources upon which they depend for livelihoods (Chambers 1987). Moreover, in some jurisdictions in developing countries, people's economic status depends on how much cattle holdings and land a person holds, not necessarily being employed and earning income (Gray and Moseley 2005). Therefore, while environmental attitudes may be driven by employment and by extension income, this may differ in different context. Further research on how employment interacts with socio-cultural conditions to drive environmental attitudes will be needed. This is particularly important because our study was unable to unpack the nature of the occupations or professions of survey participants, as well as their income-which are potential explanatory factors (e.g., Franzen and Vogl 2013).

Our results further show that there were no statistically significant differences between group means for both age: $F_{(1,275)}=0.639, p=0.425$, and educational attainment: $F_{(2,272)}=0.639, p=0.930$. This finding contradicts the claim that younger and better educated people are more environmentally concerned due to higher levels of environmental awareness. 


\section{Limitations and future research}

The data analysed in this study was based on a survey that targeted only people who: (1) had internet access, (2) are literate in the English language. This excludes non-internet users as well as those who are not literate in the English language. Given that a significant proportion of the Ghanaian public falls within the brackets excluded, we do not intend to generalise our results. Readers should therefore consider this drawback when interpreting our findings.

The data used in this study were gathered through self-stated environmental attitudes. Evidence suggests that the accuracy of such results may be affected by social desirability bias and limited memory of survey participants. Again, the inherently subjective nature of the approach means that participants' rating of attitudes depends on their environmental knowledge and beliefs, which may vary across the population (Kormos and Gifford 2014). Moreover, the statistical analysis applied in this study, the ANOVA, is unable to account for the influence of confounding variables, as well as the complex interaction between sociodemographic factors and other psychosocial variables (such as norms). The complexity of environmental attitudes requires an application of multivariate analytical techniques (e.g., structural equation modelling, conditional process modelling) to explore the mechanisms through which different factors affect one another and the conditions under which such relationships occur.

\section{Concluding remark}

The present study was designed to determine whether socio-demographic groups report different attitudes towards water resource management in coastal communities in the Greater Accra Region of Ghana. We found that females reported higher pro-environmental attitudes than men, and these differences were statistically significant. Additionally, the employed were found to have reported higher environmental attitudes than students and the unemployed, however, we do not find evidence to support the influence of age and educational attainment on environmental attitudes. The implications of our findings are that, sociodemographic factors are likely to moderate the effects of policies designed to promote positive environmental attitudes and sustainable water resource management. For instance, how people receive such policies, whether they are willing and able to support the implementation of policies or not, may depend on their employment status, all things being equal. An unemployed person may resist a ban on illegal mining - a potential cause of water pollution in Ghana-due to the need for a source of livelihood. This may not be limited to a binary categorisation of employment (i.e., employed vs. unemployed) but extends to other economic motivations; some employed people (e.g., wealthy businessmen/women) may not welcome such policies due to selfish inclinations and the desire to amass wealth. Further research is needed to unpack the complex interaction between socio-demographic variables and other psychosocial variables. This could advance our understanding of contextual factors influencing water policies.

\section{Compliance with ethical standards}

Conflict of interest The authors declare that they have no conflict of interest.

Open Access This article is licensed under a Creative Commons Attribution 4.0 International License, which permits use, sharing, adaptation, distribution and reproduction in any medium or format, as long as you give appropriate credit to the original author(s) and the source, provide a link to the Creative Commons licence, and indicate if changes were made. The images or other third party material in this article are included in the article's Creative Commons licence, unless indicated otherwise in a credit line to the material. If material is not included in the article's Creative Commons licence and your intended use is not permitted by statutory regulation or exceeds the permitted use, you will need to obtain permission directly from the copyright holder. To view a copy of this licence, visit http://creativecommons.org/licenses/by/4.0/.

\section{Appendix 1: Normality test results}

\begin{tabular}{lllllll}
\hline \multicolumn{2}{l}{ Kolmogorov-Smirnov } & & & \multicolumn{3}{l}{ Shapiro-Wilk } \\
\cline { 1 - 2 } Statistic & $d f$ & Sig. & & Statistic & $d f$ & Sig. \\
\hline 0.458 & 278 & 0.000 & & 0.289 & 278 & 0.000 \\
\hline
\end{tabular}




\section{Appendix 2: ANOVA and test of equality of variances}

1. Age

\begin{tabular}{lllll}
\hline & $\mathrm{N}$ & Mean & SD & SE \\
\hline 1 & 125 & 0.6798 & 0.08574 & 0.00767 \\
2 & 152 & 0.6868 & 0.05992 & 0.00486 \\
Total & 277 & 0.6836 & 0.07266 & 0.00437 \\
\hline
\end{tabular}

Test of homogeneity of variances

\begin{tabular}{llll}
\hline Levene statistic & $d f 1$ & $d f 2$ & Sig. \\
\hline 2.599 & 1 & 275 & 0.108
\end{tabular}

2. Gender

\begin{tabular}{lrlll}
\hline & $\mathrm{N}$ & Mean & SD & SE \\
\hline 1 & 187 & 0.6795 & 0.08558 & 0.00626 \\
2 & 89 & 0.6921 & 0.03106 & 0.00329 \\
Total & 276 & 0.6836 & 0.07279 & 0.00438 \\
\hline
\end{tabular}

Test of homogeneity of variances

\begin{tabular}{llll}
\hline Levene statistic & $d f 1$ & $d f 2$ & Sig. \\
\hline 4.907 & 1 & 274 & 0.028
\end{tabular}

3. Education

\begin{tabular}{lrlll}
\hline & \multicolumn{1}{c}{$\mathrm{N}$} & Mean & SD & SE \\
\hline 1 & 39 & 0.6875 & 0.04198 & 0.00672 \\
2 & 169 & 0.6825 & 0.07864 & 0.00605 \\
3 & 65 & 0.6833 & 0.07389 & 0.00917 \\
Total & 273 & 0.6834 & 0.07317 & 0.00443 \\
\hline
\end{tabular}

\begin{tabular}{lccc}
\hline Test of homogeneity of variances & & \\
\hline Levene statistic & $d f 1$ & $d f 2$ & Sig. \\
\hline 0.163 & 2 & 270 & 0.850 \\
\hline
\end{tabular}

4. Employment

\begin{tabular}{lrlll}
\hline & $\mathrm{N}$ & Mean & SD & SE \\
\hline 1 & 53 & 0.6701 & 0.10261 & 0.01409 \\
2 & 101 & 0.6781 & 0.09227 & 0.00918 \\
3 & 110 & 0.6936 & 0.01699 & 0.00162 \\
Total & 264 & 0.6830 & 0.07435 & 0.00458 \\
\hline
\end{tabular}

\begin{tabular}{lccc}
\hline Test of homogeneity of variances & & \\
\hline Levene statistic & $d f 1$ & $d f 2$ & Sig. \\
\hline 6.507 & 2 & 261 & 0.002 \\
\hline
\end{tabular}

\section{References}

Ajzen, I., \& Fishbein, M. (1980). Understanding attitudes and predicting social behaviour. Englewood Cliffs, NJ: Prentice-Hall Inc.

Babbie, E. (1999). The basics of social research. Belmont, CA: Wadsworth.

Beiser-Mcgrath, L. F., \& Huber, R. A. (2018). Assessing the relative importance of psychological and demographic factors for predicting climate and environmental attitudes. Climatic Change, 149(3-4), 335.

Blocker, T. J., \& Eckberg, D. L. (1989). Environmental issues as women's issues: General concerns and local hazards. Social Science Quarterly, 70(3), 586.

Blocker, T. J., \& Eckberg, D. L. (1997). Gender and environmentalism: Results from the 1993 general social survey. Social Science Quarterly, 78(4), 841-858.

Bogner, F. X. (2000). Environmental perceptions of Italian and some European non-Mediterranean pupil populations. Fresenius Environmental Bulletin, 9(9), 570-581.

Bryman, A. (2008). Social research methods. Oxford: Oxford University Press.

Chambers, R. (1987). Sustainable livelihoods, environment and development: Putting poor rural people first. IDS Discussion Paper 240, Brighton: IDS.

Cronbach, L. J. (1951). Coefficient alpha and internal structure of tests. Psychometrika, 16(3), 297-334.

Eagles, P., \& Demare, R. (1999). Factors influencing children's environmental attitudes. Journal of Environmental Education, 30(4), 33-37.

Erdogan, M., Usak, M., \& Bahar, M. (2013). A review of research on environmental education in non-traditional settings in Turkey, 2000 and 2011. International Journal of Environmental and Science Education, 8(1), 37-57.

Franzen, A., \& Vogl, D. (2013). Two decades of measuring environmental attitudes: A comparative analysis of 33 countries. Global Environmental Change, 23(5), 1001-1008. 
Gray, L. C., \& Moseley, W. G. (2005). A geographical perspective on poverty-environment interactions. Geographical Journal, 171(1), 9-23.

Hunter, L. M., Hatch, A., \& Johnson, A. (2004). Cross-national gender variation in environmental behaviours. Social Science Quarterly, 85(3), 677-694.

Karpiak, C. P., \& Baril, G. L. (2008). Moral reasoning and concern for the environment. Journal of Environmental Psychology, 28(3), 203-208.

Kasser, T. (2011). Human identity and environmental challenges. In Keynote at the NARST annual international conference, Orlando, USA.

Kormos, C., \& Gifford, R. (2014). The validity of self-report measures of pro-environmental behavior: A meta-analytic review. Journal of Environmental Psychology, 40(2014), 359-371.

Martin-Ortega, J., Glenk, K., Byg, A., \& Okumah, M. (2017). Public's views and values on peatland restoration in Scotland: Results from a quantitative study. The James Hutton Institute, Scotland's Rural College and the University of Leeds joint report.

Mensah, I. (2012). Environmental education and environmentally responsible behaviour: The case of international tourists in Accra hotels. International Journal of Tourism Sciences, 12(3), 69-89.

Morris, C., \& Potter, C. (1995). Recruiting the new conservationists: Farmers' adoption of agri-environmental schemes in the UK. Journal of Rural Studies, 11(1), 51-63.

Mostafa, M. M. (2007). Gender differences in Egyptian consumers' green purchase behaviour: The effects of environmental knowledge, concern and attitude. International Journal of Consumer Studies, 31(3), 220-229.

OECD. (2012). Water quality and agriculture: Meeting the policy challenge. OECD studies on water. Paris: Organisation for Economic Co-operation and Development.

Okumah, M., \& Ankomah-Hackman, P. (2020). Applying conditional process modelling to investigate factors influencing the adoption of water pollution mitigation behaviours. Sustainable Water Resources Management, 6(2), 17.

Okumah, M., Chapman, P., Martin-Ortega, J., \& Novo, P. (2019). Mitigating agricultural diffuse pollution: Uncovering the evidence base of the awareness-behaviour-water quality pathway. Water, 11(1), 29.

Okumah, M., Martin-Ortega, J., \& Novo, P. (2018). Effects of awareness on farmers' compliance with diffuse pollution mitigation measures: A conditional process modelling. Land Use Policy, 76, 36-45.

Okumah, M., \& Yeboah, A. S. (2019). Exploring stakeholders' perceptions of the quality and governance of water resources in the Wenchi Municipality. Journal of Environmental Planning and Management. https://doi.org/10. 1080/09640568.2019.1663724.
Okumah, M., Yeboah, A. S., \& Amponsah, O. (2020). Stakeholders' willingness and motivations to support sustainable water resources management: Insights from a Ghanaian study. Conservation Science and Practice. https://doi.org/ 10.1111/csp2.170.

Okumah, M., Yeboah, A. S., Nkiaka, E., \& Azerigyik, R. A. (2019b). What determines behaviours towards water resources management in a rural context? Results of a quantitative study. Resources, 8(2), 109.

Schultz, P. W., Shriver, C., Tabanico, J. J., \& Khazian, A. M. (2004). Implicit connections with nature. Journal of Environmental Psychology, 24(1), 31-42.

Schultz, P. W., \& Zelezny, L. (1999). Values as predictors of environmental attitudes: Evidence for consistency across 14 countries. Journal of Environmental Psychology, 19(3), 255-265.

Stern, P. C., \& Dietz, T. (1994). The value basis of environmental concern. Journal of Social Issues, 50(3), 65-84.

Thompson, S., \& Barton, M. A. (1994). Ecocentric and anthropocentric attitudes toward the environment. Journal of Environmental Psychology, 14(2), 149-157.

Tindall, D. B., Davies, S., \& Mauboules, C. (2003). Activism and conservation behavior in an environmental movement: The contradictory effects of gender. Society \& Natural Resources, 16(10), 909-932.

United Nations. (2016a). Global sustainable development report 2016. New York: Department of Economic and Social Affairs.

United Nations. (2016b). Water and Sanitation interlinkages across the 2030 agenda for sustainable development. Geneva: UN-Water.

United Nations Environment Programme. (2017). Towards a pollution free planet background report. Nairobi: United Nations Environment Programme.

United Nations World Water Assessment Programme. (2015). The United Nations world water development report 2015: Water for a sustainable world. Paris: United Nations Educational, Scientific and Cultural Organization.

Young, C., Morris, C., \& Andrews, C. (1995). Agriculture and the environment in the UK: Towards an understanding of the role of 'farming culture'. Greener Management International, 63, 80.

Zelezny, L. C., Chua, P. P., \& Aldrich, C. (2000). Elaborating on gender differences in environmentalism. Journal of Social Issues, 56(3), 443-457.

Zeus, J. H., \& Reif, K. (1990). Evolution of environmental attitudes in the European Community. Scandinavian Political Studies, 13(2), 119-146.

Publisher's Note Springer Nature remains neutral with regard to jurisdictional claims in published maps and institutional affiliations. 